\title{
ENVOLVIMENTO DOCENTE NA INTERPRETAÇÃO DO SEU TRABALHO: UMA ESTRATÉGIA METODOLÓGICA
}

\author{
ADRIANA DUARTE \\ driduarte@fae.ufmg.br \\ DALILA ANDRADE OLIVEIRA \\ dalila@fae.ufmg.br \\ Faculdade de Educação da Universidade Federal de Minas Gerais - FAE/UFMG \\ MARIA HELENA AUGUSTO \\ malena.oga@gmail.com \\ SAVANA MELO \\ savanadiniz@yahoo.com.br \\ Doutorandas do Programa de Pós-Graduação da FAE/UFMG
}

RESUMO

O artigo discute a metodologia em desenvolvimento em projeto de pesquisa que tem como objeto a análise do trabalho docente, considerando sua natureza, configurações e sentidos. $O$ texto apresenta as escolhas teórico-metodológicas efetuadas, o trabalho realizado em campo com os docentes e os resultados preliminares obtidos. As conclusões confirmam a expectativa inicial dos pesquisadores quanto à capacidade manifesta pelos professores de se envolverem na análise do próprio trabalho e à confiança no trabalho coletivo e na possibilidade de mudanças a partir da sua organização.

POLITICAS EDUCACIONAIS - PROFESSORES - TRABALHO - MÉTODOS DE PESQUISA

Este artigo baseou-se na pesquisa Gestão Escolar e Trabalho Docente: as Reformas Educacionais em Curso nas Redes Públicas de Minas Gerais, financiada pelo Conselho Nacional de Desenvolvimento Científico e Tecnológico - CNPq - e pela Fundação de Amparo à Pesquisa do Estado de Minas Gerais - Fapemig -, realizada pelo Grupo de Pesquisa Política Educacional e Trabalho Docente - Gestrado -, no qual as autoras atuam, sob a coordenação de Dalila Andrade Oliveira, também fundadora do grupo. Criado em 2002, na FAE/UFMG, o Gestrado é associado à Rede Latino-Americana de Estudos sobre Trabalho Docente, vinculada ao Conselho Latino-Americano de Ciências Sociais - Clacso. 


\begin{abstract}
TEACHERS'INVOLVEMENT IN THE INTERPRETATION OF THEIRWORK: A METHODOLOGICAL STRATEGY. By taking into account the nature, configurations, and meanings of the teaching work as its analysis object, this article discusses the methodology being developed in a research project. The text addresses the methodological-theoretical choices made, the field work done with teachers and the preliminary results achieved. The conclusions confirm the researchers' initial expectation concerning the ability expressed by teachers of getting involved in the analysis of their own work, the confidence in the collective work and the possibility of changes by means of their organization. EDUCATIONAL POLICIES - TEACHERS - LABOUR - RESEARCH METHODOLOGY
\end{abstract}

Este artigo, apoiado em pesquisa sobre gestão escolar e trabalho docente, analisa o método utilizado no trabalho de campo e alguns resultados preliminares, obtidos por meio de experiência-piloto realizada em uma escola estadual localizada em cidade do interior do Estado de Minas Gerais.

A pesquisa tem por objeto o trabalho docente, considerando sua natureza, configurações e sentidos. Visa identificar e analisar as mudanças ocorridas na organização do trabalho na escola e no exercício da profissão docente, com base nas reformas implementadas nas redes públicas de ensino de Belo Horizonte e de Minas Gerais desde 1990. Tais mudanças circunscrevem-se no quadro de reformas que os países latino-americanos passaram a viver a partir dos anos 1980.

Parte-se do pressuposto de que o trabalho docente compreende não só aquele realizado em sala de aula, como também o processo que envolve o ensino e a aprendizagem e, ainda, a participação do professor no planejamento das atividades, na elaboração de propostas político-pedagógicas e na própria gestão da escola, incluindo formas coletivas de realização do trabalho escolar e de articulação da escola com as famílias e a comunidade.

A metodologia adotada pauta-se no trabalho coletivo empreendido tanto pelos pesquisadores quanto pelos sujeitos pesquisados. Por essa razão, as relações estabelecidas na pesquisa são orientadas pela busca da horizontalidade e da autonomia nos processos educativos. Isso pressupõe envolvimento dos professores no processo de investigação não como meros informantes, mas como sujeitos autorizados e estimulados a pensar sobre o seu trabalho, sobre as dificuldades existentes e dispostos a contribuir para sua interpretação. Em- 
Envolvimento docente...

bora de maneira desigual, esses pressupostos foram confirmados em campo, mediante a participação dos professores na identificação dos problemas e na análise do trabalho coletivo exercido na escola-piloto, o que será demonstrado adiante.

Cabe salientar que essa metodologia traz para o trabalho de pesquisa um rico material que, expressado em um coletivo de professores, emerge de suas análises como sujeitos envolvidos: conhecimentos, conceitos, expectativas, temores, dúvidas, opiniões, atitudes, práticas, conflitos, acordos etc. Nesse sentido, a metodologia oferece aos pesquisadores a oportunidade para desenvolver teorizações que dão suporte a novas e proveitosas análises e inferências relacionadas com o problema em questão. $\bigcirc$ envolvimento dos sujeitos, professores, na análise de seu trabalho não retira, portanto, dos pesquisadores a preocupação epistemológica a respeito do tratamento da realidade analisada e a preocupação metodológica em torno da fundamentação científica.

\section{AS ESCOLHAS TEÓRICO-METODOLÓGICAS}

A escola como instituição que desempenha um papel social e, ao mesmo tempo, constitui-se em local de trabalho é caracterizada por uma multiplicidade de relações. Para investigá-la, faz-se necessária a adoção de um enfoque teórico-metodológico que possibilite a análise de suas dimensões objetivas em profundidade e extensão, assim como a apreensão e a interpretação das percepções dos sujeitos que nela atuam acerca do problema que se deseja conhecer.

A abordagem qualitativa responde a essas condições, uma vez que se preocupa com o universo dos significados, das ações e das relações humanas e reconhece os sujeitos envolvidos na investigação como capazes de elaborar conhecimentos e de produzir práticas para intervir nos problemas que identificam. O pesquisador desempenha papel fundamental, porém, o conhecimento é concebido aqui como uma obra coletiva em que todos os envolvidos, inclusive os pesquisados, podem identificar criticamente seus problemas e suas necessidades, encontrar alternativas e propor estratégias adequadas de ação (Chizzotti, 1998, p.83; Minayo, 2002, p.22).

Acredita-se que a produção do conhecimento tem um caráter interativo. professor é sujeito do processo em que se produz o conhecimento sobre 
ele. A comunicação desempenha um papel fundamental nesse processo e constitui o espaço no qual o sujeito estudado vai amadurecendo e construindo, de forma coletiva e cada vez mais complexa, sua expressão, condição essencial para o conhecimento que se constrói. Manifesta-se, assim, uma natureza construtivo-interpretativa em um processo vivo em permanente desenvolvimento, no qual se realizam e se legitimam formas muito diversificadas como a elaboração pelos próprios sujeitos de suas expectativas sobre os resultados esperados.

Dentro da abordagem qualitativa, utiliza-se como referencial a concepção dialética segundo a qual o fenômeno ou processo social deve ser entendido nas suas determinações e transformações dadas pelos sujeitos (Minayo, 1996, p.65). O método dialético, para Triviños, é capaz de "assinalar as causas e conseqüências dos problemas, suas contradições, suas relações, suas qualidades, suas dimensões quantitativas, se existem, e realizar, através da ação, um processo de transformação da realidade, que interessa" (1987, p. | 25).

Para Frigotto (1989, p.70-90), no materialismo histórico, o homem é produto do social e deve ser considerado concretamente, ou seja, situado no tempo e no espaço, inserido em um contexto histórico-econômico-culturalpolítico. $\bigcirc$ homem é sujeito da sua ação. As concepções de homem e de mundo são consideradas conjuntamente. As interações homem-mundo e sujeito-objeto são imprescindíveis para que o ser humano se torne sujeito de sua práxis. Por sua vez, a educação é vista como uma atividade mediadora no seio da prática social global. Em síntese, o materialismo histórico permite o levantamento de questões sobre a construção da sociedade e centra-se no conhecimento como fruto do contexto histórico.

A abordagem qualitativa na perspectiva dialética mostrou-se a mais adequada para o alcance dos objetivos propostos na pesquisa, considerando o objeto estudado. Foram adotados ainda alguns elementos da pesquisa-ação, da pesquisa participante e de grupos focais. Contudo, nenhum desses procedimentos foi aplicado na sua integralidade, mas reordenado dentro da lógica proposta pela investigação. Assim, pode-se considerar que a opção metodológica deste trabalho não se prende a um modelo puro, é uma combinação de aproximações de diferentes modelos.

A pesquisa foi estruturada em duas etapas: a primeira consistiu em uma revisão da literatura, com o intuito de mapear a produção acadêmica na área; a segunda, em um trabalho de campo em quatro escolas das redes públicas, 
Envolvimento docente...

duas da rede municipal de Belo Horizonte e duas da rede estadual de Minas Gerais, entre as quais se localiza o projeto-piloto já referido. $\bigcirc$ objetivo é analisar a complexidade das novas situações que abarcam o cotidiano da organização escolar e as relações de trabalho na escola.

trabalho de campo na escola-piloto foi realizado por meio de encontros planejados pelo grupo de pesquisa, tomando por base a definição de uma temática a ser abordada com os docentes; o resultado de cada encontro subsidiava o planejamento dos seguintes. Para estimular a reflexão, a discussão, a fala e a construção de sentidos foram adotadas técnicas afinadas com o objetivo da pesquisa de buscar a expressão e a reflexão dos docentes acerca da sua realidade de trabalho e das relações sociais que a compõem (Oliveira, 1992). Procurava-se identificar situações que caracterizam o espaço escolar, a organização e as condições de trabalho, o controle do tempo, a intensificação e a precarização do trabalho, entre outras. Optou-se por utilizar, no trabalho de campo, fotografias e filmagens, além de anotações, por se considerar que o registro visual proporciona a documentação de momentos ou situações que ilustram a riqueza do trabalho desenvolvido.

\section{O TRABALHO DE CAMPO: DESCOBERTA E CRIAÇÃO}

O primeiro encontro foi organizado objetivando a apresentação da proposta de pesquisa e a vivência da metodologia a ser utilizada. A adesão ocorreu "praticamente por unanimidade", embora tenham transparecido incertezas do tipo: "O que nós vamos ganhar com isso?"

Os trabalhos foram iniciados com uma técnica projetiva denominada Portal, em que os professores representaram seus sentimentos por meio de colagens ao entrar e sair do local de trabalho. Pretendia-se com isso que eles refletissem sobre a complexidade do trabalho na escola.

Os professores revelaram preocupação com a qualidade da educação, com o reconhecimento da intensificação do trabalho docente e da precariedade financeira, manifestando ainda inquietação com as conseqüências desses aspectos sobre o processo de trabalho e com a própria formação continuada. "Estamos nos transformando em máquinas, que educação é essa? [...] $\bigcirc$ tempo não dá para fazer tantas coisas que precisam ser feitas. [...] Precisava de um avião ou de uma moto bem potente..." (Professor A). 
A ambigüidade em face do trabalho está presente no sentimento de relativa autonomia e auto-responsabilização e, ao mesmo tempo, de desconforto por se sentirem sozinhos. "O trabalho é um desafio e um desafio solitário. [...] A gente se enxerga sozinho, não consegue se enxergar como coletivo. $\bigcirc$ trabalho é nosso mesmo" (Professor B).

Os professores questionam as mudanças operadas nas escolas, que se expressam em uma crise de confiança no sentido e na qualidade da educação e têm repercussões sobre o seu trabalho. A intensificação do trabalho é crescente, mas as condições de sua realização alteram-se pouco, deixando-os mais expostos a críticas e responsabilizando-os individualmente pelos males que atingem a escola.

No segundo encontro, propôs-se a discussão sobre a relação dos trabalhadores com o tempo, focalizando a produção e a reprodução da vida. Para tanto, utilizou-se a "técnica do relógio": cada participante fez um registro de como ocupava as vinte e quatro horas do seu dia. $\bigcirc$ objetivo era dimensionar o tempo despendido pelos professores com as atividades que compõem o seu cotidiano, tais como: preparação para o trabalho, jornada de trabalho, ritmo, disciplina, divisão sexual do trabalho, tempo de locomoção, trabalho doméstico, dupla jornada, lazer, descanso e tempo dedicado à família.

A discussão em grupo realizada pelos professores sobre os seus "relógios" levou-os a refletir sobre as obrigações do trabalho no dia-a-dia e a interferência disso na sua vida. Eles se depararam com a realidade da organização do tempo destinado à sua vida pessoal e daquele reservado ao trabalho, e a compararam com as dos demais colegas, passando da percepção individual a uma percepção coletiva.

A discussão desse tema foi complementada com leitura e debate de texto (Thompson, 1991) em pequenos grupos, o que revelou excesso de tempo dedicado ao trabalho e carência no que se refere ao lazer e à família: "O horário de trabalho é que organiza os outros horários de nossa vida..." (Professor C).

Mesmo fora da escola, os professores desempenham tarefas concretas relacionadas à docência, além de se preocuparem com os alunos. A preparação das aulas, por exemplo, acontece na maioria das vezes à noite, juntamente com outras atividades, como assistir a TV, ou mesmo orientar as tarefas escolares dos filhos, uma vez que parcela significativa de professores trabalha em dois turnos ou mais (na mesma escola ou em escolas diferentes). Há também 
Envolvimento docente...

a presença marcante do trabalho doméstico entre as professoras, que representa uma carga de trabalho agregada. Com isso, o tempo de descanso e de lazer e o espaço para a criação eram comprometidos, reforçando a idéia de homem-máquina com uma rotina alienante: "O trabalho é estressante e transforma o homem em máquina, o professor em máquina. $\bigcirc$ tempo regula a organização, o planejamento, a execução, tudo. $\bigcirc$ tempo vai alienando o homem..." (Professor D).

Na sociedade capitalista ocorre uma demarcação muito definida entre o tempo de trabalho e aquele não vinculado a essas obrigações. Pode-se considerar que o tempo de reprodução da força de trabalho é subsumido ao tempo de produção. Para ser realizado como previsto, o conjunto das atribuições docentes excede em horas a jornada semanal de trabalho remunerado, o que obriga os professores a dedicar mais tempo do que aquele pelo qual recebem os seus salários.

Nesse encontro com os docentes foram tratados ainda os temas "relações de poder na escola" (Tratemberg, 2002) e "humana docência" (Arroyo, 2002), a partir da leitura e debate de textos. Das falas dos professores, podese destacar o entendimento sobre a desumanização do trabalho docente e a necessidade de humanizar as relações entre professores e alunos. A necessidade de reconhecer os alunos como sujeitos individuais e históricos surge como preocupação importante, assim como a constatação de que os alunos freqüentam a escola em diferentes condições e por motivações diversas. A escola pode significar a oportunidade de acesso à renda mínima e à alimentação.

Humana docência seria... nós estarmos lidando com o ser humano e não com receptores ou máquinas, que estão ali e vão receber uma certa dosagem de conhecimento diário... É preciso entender os conflitos. [...] Os alunos vêm à escola, pra quê? $\bigcirc$ que eles estão levando daqui ou o que eles estão trazendo? Muitas vezes vêm, [...] pra receber o Bolsa-Escola, ou pra merendar [...] E o aprendizado? E uma perspectiva de vida? A gente não está percebendo isso... (Professor E)

Na sua relação, professores e alunos apresentam questões que são de ordem econômica, social e institucional e que se manifestam na escola como problemas relativos à fome, ao uso de drogas, à sexualidade, a doenças, a preconceitos. Trata-se de questões tão complexas e que exigem soluções tão 
imediatas que o docente é constantemente assaltado por dúvidas, incertezas, indecisões, quando não por apatia e por desespero (Santos, 2002). Alguns desses professores buscam solitariamente alternativas para superar isso, o que agrava o sentimento de culpa quando não obtêm sucesso. Outros evitam se envolver com questões que não sejam específicas do ensino-aprendizagem e dos "muros da sala de aula".

As exigências do trabalho docente têm mudado com o tempo, sendo maiores as responsabilidades, mais difusos os papéis, mais diversificadas as estratégias de ensino e de avaliação. $O$ controle sobre os professores por meio dos programas prescritos, os currículos definidos e os métodos de instrução cobram esforços cada vez maiores, em condições que, no melhor dos casos, são estáveis, quando não se deterioram dia a dia.

terceiro encontro centrou-se na discussão dos temas "processo de trabalho", "organização escolar" e "organização do trabalho escolar", e foi iniciado com uma aula dialogada. Posteriormente, os professores foram divididos em dois grandes grupos, de acordo com a experiência relacionada ao tempo de docência, um com menos de dez anos e o outro com mais de dez anos de trabalho efetivo no magistério. Os grupos tinham como tarefa representar o processo de trabalho na escola, no respectivo período, a partir de sua vivência. Essa representação se deu por meio da técnica painel, em que os grupos retrataram a escola, seus sujeitos e papéis, equipamentos e mobiliários, a organização do espaço físico e as relações de poder.

Os painéis construídos pelos professores e as discussões realizadas foram extremamente ricos e reveladores de sua percepção sobre as mudanças na organização escolar e na organização do trabalho na escola nessas últimas décadas. As imagens mostraram, antes mesmo da apresentação dos grupos, as grandes mudanças operadas. Os docentes acabaram por produzir paradigmas da escola referentes aos dois períodos.

A "escola há mais de dez anos" foi representada por uma definição clara e hierárquica dos papéis e das atividades que eram executadas: o diretor foi localizado no topo da hierarquia, centralizando decisões, seguido do vicediretor e dos especialistas:

Na verdade quando se fala que o diretor estava acima dos outros, é que quando ele dava uma ordem, não se discutia. [...] Ele não pedia opinião pra ninguém, 
Envolvimento docente...

ele chegava "vai ser assim" e era mesmo... [...] Era uma relação de poder forte mesmo.... [...] Na hierarquia tinha o orientador e o supervisor... [...] Depois é que vinham os professores. (Professor F)

No painel, os professores figuravam abaixo dos especialistas e separados dos alunos, com os quais não havia diálogo. Já os pais foram representados fora da escola. A disciplina foi considerada rígida, e o medo, destacado como mediador das relações. Segundo a avaliação dos participantes, a escola tinha maior credibilidade por parte dos alunos e professores, sendo estes mais reconhecidos.

A conclusão para o nosso grupo é que há dez anos a escola tinha mais credibilidade, acreditava-se mais na escola e nas coisas que ela ensinava e hoje em dia até mesmo o professor está tendo essa dúvida: "o que eu estou ensinando vai valer realmente pra que o aluno quer, pra que o aluno busca?" (Professor $\mathrm{G}$ )

A "escola atual" foi representada já inserindo os novos padrões de organização do trabalho escolar, quais sejam: organização flexível, não hierárquica, com a fusão de papéis e funções dos trabalhadores, revelando maior proximidade entre os sujeitos e maior liberdade por parte dos alunos. O papel do diretor foi identificado como não restrito à administração, envolvendo também atividades pedagógicas, assim como o dos demais trabalhadores da escola, o que foi assinalado como um avanço em relação à escola anterior.

O fato de o diretor ter se envolvido pedagogicamente, eu acho que é importante. Todos os membros da escola estarem envolvidos com o pedagógico, não é mais só o gabinete, só a parte administrativa. Hoje a escola está organizada para isso. Isso é bom porque você tem com quem dividir, você tem onde buscar. [...] Então eu acho que isso, no meu ponto de vista, um grande avanço que nós tivemos, eu acho positivo. (Professor $\mathrm{H}$ )

No entanto, constatou-se que há uma desorganização da escola, desorganização vista, ao mesmo tempo, como positiva e negativa. Se, por um lado, 
rompeu-se a hierarquia rígida presente na escola anterior, por outro, gerouse um sentimento de perda em relação à identificação dos papéis ora desempenhados, desconhecendo-se a quem recorrer em determinadas situações.

A gente vê uma desorganização positiva e negativa na escola. Positiva, porque os diretores e todos nós saímos do pedestal, mas é negativo no ponto em que as pessoas não sabem mais o que têm que fazer, qual é a sua função. Nós, professores não sabemos a quem recorrer, muitas vezes a desorganização causa isso. [...] Os especialistas estão interagindo de certa forma, mas na grande parte das vezes não é porque eles têm um trabalho conjunto e multidisciplinar ou interdisciplinar. Muitas vezes um está suprindo a falta do outro. (Professor I)

Verificou-se também um descontentamento dos professores no que se refere às normas e ordens emanadas dos gestores dos sistemas de ensino, consideradas distantes do contexto escolar e restritivas ao exercício da autonomia da escola.

A eleição do diretor não modifica muito essa relação da Escola com o Estado. $O$ diretor não tem autonomia, porque tudo esbarra na Secretaria, esbarra na legislação. [...] Na realidade a escola gira em torno do sistema, fazendo tudo que vem de lá, porque não tem outra saída. A gente se adapta e tenta fazer o meIhor se virando daquele jeito que pode. [...] São ordens, que às vezes nem são normas, são ordens... (Professor J)

Tomando por base os depoimentos dos professores, pode-se considerar que a escola tradicional, transmissiva, autoritária e burocrática mudou de alguma forma. Isso não significa que a escola atual seja democrática, pautada no trabalho coletivo, na participação dos sujeitos e com uma educação de qualidade. $\bigcirc$ trabalho pedagógico foi reestruturado e espera-se mais do docente em termos de participação na gestão, nas instâncias de representação das escolas (colegiados e conselhos), nos trabalhos coletivos, nas relações com pais e comunidade. Entretanto, por se tratar de local de trabalho, onde diferentes interesses se confrontam, surgem, muitas vezes, contradições entre a lógica da racionalidade da administração e as inadequadas condições de trabalho que 
sobrecarregam os professores. Os salários se deterioraram, o que indica um processo de precarização do trabalho docente, e a comunidade ainda se encontra fora da escola, desconhecendo o direito de participar (Oliveira, 2002).

O quarto encontro com os professores teve como temática central a saúde do trabalhador docente. Cada professor recebeu uma transparência dispositivo produzido em folha translúcida - com uma silhueta de seu corpo, onde ele deveria marcar as partes em que sentia o efeito do trabalho. Essa técnica permite evidenciar sintomas relacionados às particularidades da profissão, mostrando que, muitas vezes, isso não acontece de forma individual, ou seja, vários do mesmo grupo profissional relatam os mesmos sintomas. Essas transparências individuais sobrepostas possibilitaram a indicação de um quadro coletivo de sintomas dos professores: tensão nervosa, problemas de voz, dores nas pernas, na garganta, nas mãos, no abdômen, nos ombros, na nuca e no coração.

Posteriormente, os professores indicaram, no painel da escola atual, os locais, as pessoas, as situações que provocavam os sintomas indicados nas siIhuetas. As principais preocupações apontadas foram: o aprendizado e a freqüência dos alunos; a desorganização da escola; as constantes mudanças nas normas; a sobrecarga de trabalho; a diversidade de idéias e pensamentos; o trabalho com a diferença; a falta de recursos; o bem-estar coletivo; os problemas sociais dos alunos e a responsabilidade, a autocobrança e os limites da ação dos docentes.

As preocupações dos professores em relação aos sintomas, constantes no quadro I, são elucidativas de suas percepções.

Esses depoimentos mostram que os professores se sentem obrigados a responder às novas demandas pedagógicas e administrativas advindas das reformas educacionais e concretizadas no cotidiano da escola. Observa-se ainda que a dinâmica imposta por tais políticas produz no cotidiano escolar relações distintas entre os professores, seu trabalho e sua identidade profissional. Esse processo forja a subjetividade docente, ou seja, esses profissionais se auto-responsabilizam pelas falhas ocorridas na escolarização de seus alunos e por outros problemas que surgem na escola. Isso explica os altos índices de afastamento por estresse (Gasparini, 2005).

Na rede estadual de Minas Gerais, os dados sobre adoecimento dos trabalhadores docentes são alarmantes. Quatro em cada cem professores encon- 
QUADRO I

DEPOIMENTOS DOS PROFESSORES SOBRE

OS AGENTES GERADORES DE SINTOMAS

\begin{tabular}{|l|l|}
\hline $\begin{array}{l}\text { Agente gerador } \\
\text { de sintomas }\end{array}$ & $\begin{array}{l}\text { Depoimentos } \\
\text { Aprendizado } \\
\text { dos alunos }\end{array}$ \\
$\begin{array}{l}\text { Constantes } \\
\text { e o retorno também, então o que vai me deixar feliz ou infeliz no momento } \\
\text { depende da aprendizagem dele..." (Professor K). }\end{array}$ \\
$\begin{array}{l}\text { normanças nas } \\
\text { "Eu esbarro nas normas... Eu acho que mudam de plano antes que a gente se } \\
\text { acostume com eles, na verdade é isso, é isso que atrapalha o ensino... [...] Eu } \\
\text { não sou conservadora, mas eu acho que essas mudanças confundem muito a } \\
\text { gente..." (Professor L). } \\
\text { de idéias e } \\
\text { pensamentos }\end{array}$ & $\begin{array}{l}\text { "[...]A gente que trabalha como gestor trabalha com a diferença, com essa } \\
\text { diversidade de idéias, de pensamentos. [...] A gente tem que sair da gente pra } \\
\text { atender o outro e com isso acaba não olhando a gente mesmo". (Professor M) }\end{array}$ \\
\hline $\begin{array}{l}\text { Falta de recursos } \\
\text { e problemas sociais } \\
\text { dos alunos }\end{array}$ & $\begin{array}{l}\text { "Nós temos vários problemas com os alunos que às vezes exigem psicólogos, } \\
\text { que exigem recursos... Nós não temos a verba. [...] Meu maior problema no } \\
\text { momento é este: o que eu posso fazer por esses alunos" (Professor N). }\end{array}$ \\
\hline $\begin{array}{l}\text { Responsabilização } \\
\text { e autocobrança }\end{array}$ & $\begin{array}{l}\text { "Me incomoda muito a cobrança sobre mim mesma. Isso também me deixa } \\
\text { meio doente. É... a gente querer colocar tudo nas costas. É... essa } \\
\text { autocobrança, responsabilidade" (Professor O). }\end{array}$ \\
\hline
\end{tabular}

Fonte: Relatórios dos Encontros ( ${ }^{\circ}$ ao $5^{\circ}$ ) realizados na escola-piloto (2004-2005).

tram-se na situação de ajustamento funcional'. A impossibilidade dos professores de realizar o trabalho como gostariam, a desmotivação pessoal, a insatisfação profissional, a indisposição em face das exigências, o descrédito quanto às propostas de mudança, a autodepreciação, o sentimento de desistência e abandono geram um mal-estar que pode conduzir ao adoecimento.

$\bigcirc$ quinto e último encontro na escola-piloto teve como foco a identificação das estratégias dos professores no enfrentamento de problemas relati-

I. O ajustamento funcional corresponde à situação do profissional que, por motivo de adoecimento provocado pelo exercício das funções próprias do cargo, se vê impedido de exercê-lo. Adquire o direito, após laudo médico do Serviço de Saúde do Estado, de assumir outras funções, em que não necessite executar as atividades consideradas a causa do adoecimento (Augusto, 2004). 
Envolvimento docente...

vos ao seu trabalho. Propôs-se que individualmente os participantes registrassem um problema ocorrido em seu trabalho, a estratégia utilizada e o motivo da escolha. As experiências foram debatidas em subgrupos e, posteriormente, em plenária.

Entre os problemas manifestados, predominaram os que se referem à relação professor/aluno, dificuldades de aprendizagem, indisciplina, problemas sociais, uso de drogas, violência dos alunos e o despreparo dos professores para lidar com essas situações. Em menor número, apareceram aspectos relativos às condições de trabalho: excesso de trabalho, desvalorização do magistério, desmotivação dos docentes e baixos salários.

As estratégias utilizadas em relação aos aspectos mencionados foram pontuais, predominando intervenções restritas à mudança de procedimentos e posturas nos sujeitos envolvidos. Embora tenha predominado o enfrentamento individual dos problemas, em alguns momentos foram relatados esforços no sentido de compartilhar a discussão e a busca de soluções coletivas.

Os encontros foram concluídos com um processo de avaliação do trabalho do qual participaram todos os docentes da escola. Entre os aspectos levantados nessas avaliações, destaca-se que a pesquisa possibilitou crescimento e fortalecimento do grupo, o que se traduziu na capacidade que seus membros adquiriram de refletir sobre si mesmos, sobre as condições de trabalho individual e coletivo, sobre o que se pretende e o que se pode fazer. $\bigcirc$ coletivo docente ressaltou o respeito com que foi tratado no decorrer da investigação e o quanto os professores passaram a se sentir mais seguros. Eles compreenderam que talvez não possam fazer muito pelo ensino, mas que sempre podem fazer algo. Afirmam que o trabalho abriu horizontes, despertando a vontade de lutar pela educação.

Eu acho que foi assim, um crescimento muito grande... por nós estarmos refletindo sobre nós, sobre nosso trabalho, sobre aquilo que a gente quer, sobre aquilo que a gente pode [...] Tenho certeza de que nós não vamos ser as mesmas e os mesmos, isso que é o melhor e a gente cresce muito com isso. (Professor $P$ )

Vendo essa situação toda de conflito que nós vivemos, eu senti que aquilo que eu achava que acontecia só comigo, que era minha, é uma coisa coletiva. [...] Já 
que o problema é generalizado, não sou só eu, é porque nós precisamos mudar, fazer alguma coisa. Eu acho que esse contato abriu horizontes, [...] mais gente pensando da mesma forma, então vamos lutar, não vamos desanimar, não sou só eu. Acho que isso foi muito importante. (Professor Q)

\section{CONSIDERAÇÕES FINAIS}

As mudanças na organização escolar introduzidas a partir das reformas educacionais mais recentes fizeram surgir outra realidade nas escolas, e com ela, novos problemas. Para apreendê-los, constatou-se que seria necessário construir um desenho metodológico próprio, já que nenhum dos modelos classicamente estabelecidos no paradigma qualitativo atendia integralmente aos propósitos da pesquisa. E foi exatamente isso que o grupo de pesquisa buscou construir.

Tais mudanças caracterizam-se por situações de intensificação, de flexibilização, de precarização do trabalho docente, que precisam ser identificadas, analisadas e avaliadas por aqueles que, no dia-a-dia, exercem o seu ofício. Elas indicam a existência de distanciamento e divergência entre o que se propugna nas reformas educacionais e o que é passível de realização na prática escolar. A percepção da contradição pelos próprios docentes permitiu aos profissionais compreender isso, expressar seus anseios, expectativas e necessidades de alteração nas condições de trabalho.

A metodologia de trabalho empregada nesta experiência tinha essa pretensão, e foi possível observar o processo de crescimento e desenvolvimento dos próprios participantes nesse sentido. Se, em relatos iniciais, alguns revelavam incertezas quanto ao trabalho que seria realizado, nos últimos encontros os depoimentos ressaltam o significado do que foi vivenciado pelos profissionais, tanto no que refere ao seu trabalho quanto à sua vida pessoal.

A gente ficava assim, antes do primeiro encontro, naquela expectativa... será o que eles querem da gente... Eu mesma questionei muito isso, foi uma das perguntas que nós fizemos pra vocês naquele primeiro dia. Eu acredito que a gente ganhou muito mais do que as propostas que vocês nos fizeram... E nós ganhamos muito em segurança. [...] Eu acho que a gente sabe que talvez a gente possa pouco, mas que a gente pode. Então eu acho que vocês abriram pra gente esse canal, essa esperança que a gente pode crescer. (Professor R) 
Envolvimento docente...

Os relatos confirmam a capacidade dos professores de se envolverem na análise do próprio trabalho, assim como a confiança na construção do trabalho coletivo e na possibilidade de mudanças a partir de sua própria organização. Considera-se que a pesquisa se constituiu em um espaço de formação dos professores, ultrapassando as expectativas iniciais do grupo de pesquisadores envolvidos.

A experiência possibilitou exercitar a imaginação para forjar um trabaIho, um caminho de investigação que abrisse novos horizontes em termos de perspectivas para se chegar ao conhecimento que envolve o homem e suas criações. O convite realizado por Mills ( 1972 ) de usar a imaginação sociológica e ser um bom artesão na construção metodológica ecoou como grande estímulo a esse desafio que se coloca para as outras escolas que compõem o universo da pesquisa.

\section{REFERÊNCIAS BIBLIOGRÁFICAS}

ARROYO, M. Oficio de mestre. Petrópolis: Vozes, 2002. A Humana docência, p.50-67.

AUGUSTO, M. H. O. G. Trabalho docente e organização escolar na rede estadual de ensino em Minas Gerais. Belo Horizonte, 2004. Dissert. (mestr.) Faculdade de Educação da Universidade Federal de Minas Gerais.

CHIZZOTTI, A. Pesquisas em ciências humanas e sociais. 2.ed. São Paulo: Cortez, 1998.

FRIGOTTO, G. O Enfoque da dialética materialista histórica na pesquisa educacional. In: FAZENDA, I. (org.) Metodologia da pesquisa educacional. São Paulo: Cortez, 1989. p.69-90. (Biblioteca da Educação, série I: Escola, v. II).

GASPARINI, S. M. Transtornos mentais em professores da Rede Municipal de Belo Horizonte. Belo Horizonte, 2005. Dissert. (mestr.) Faculdade de Medicina da Universidade Federal de Minas Gerais.

MILLS, C. W. A Imaginação sociológica. Rio de Janeiro: Jorge Zahar, 1972.

MINAYO, M. C. O Desafio do conhecimento: pesquisa qualitativa em saúde. São Paulo e Rio de Janeiro: Hucitec, Abrasco, 1996.

Pesquisa social: teoria, método e criatividade. Petrópolis: Vozes, 2002.

Ciência, técnica e arte: o desafio da pesquisa social, p.9-30. 
OLIVEIRA, D. A. Mudanças na organização e na gestão do trabalho na escola. In: OLIVEIRA, D.; ROSAR, M. F. Política e gestão da educação. Belo Horizonte: Autêntica, 2002. p. I25-I 44.

OLIVEIRA, D. A. As Organizações por local de trabalho: entre a ruptura e o consentimento. Belo Horizonte, 1992. Dissert. (mestr.) Faculdade de Educação da Universidade Federal de Minas Gerais.

SANTOS, L. L. C. P. Políticas públicas para o ensino fundamental: parâmetros curriculares nacionais e sistema nacional de avaliação (SAEB). Educação e Sociedade, Campinas, v.23, n.80, p.349-370, set. 2002.

THOMPSON, E. P. O Tempo, a disciplina do trabalho e o capitalismo industrial. In: TADEU, T. (org.) Trabalho, educação e prática social. Porto Alegre: Artes Médicas, 1991. p.44-93.

TRATEMBERG, M. Relações de poder na escola. In: OLIVEIRA, D.; ROSAR, M. F. (orgs.) Política e gestão da escola. Belo Horizonte: Autêntica, 2002. p. I l- 16.

TRIVIÑOS, A. N. S. Introdução à pesquisa em ciências sociais: a pesquisa qualitativa em educação. São Paulo: Atlas, 1987.

Recebido em: agosto 2006

Aprovado para publicação em: setembro 2007 